\title{
LIAPUNOV FUNCTIONS AND GLOBAL EXISTENCE
}

\section{BY AARON STRAUSS ${ }^{1}$}

Communicated by W. Rudin, December 11, 1964

Liapunov functions have been used to characterize the stability, the asymptotic stability, and the boundedness of solutions of ordinary differential equations. The purpose of this announcement is to characterize the continuability of solutions. Details and applications will appear elsewhere [6].

Consider the equation

$$
x^{\prime}=f(t, x) \quad\left(\prime=\frac{d}{d t}\right)
$$

where $x$ and $f$ belong to $E^{n}, f(t, 0)=0$ for $t \geqq 0$, and $f$ is continuous and locally Lipschitzian on $D, D=\left\{(t, x): t \geqq 0, x \in E^{n}\right\}$. For $\left(t_{0}, x_{0}\right)$ $\in D$, let $F\left(t, t_{0}, x_{0}\right)$ be that solution of (E) for which $F\left(t_{0}, t_{0}, x_{0}\right)=x_{0}$.

Definition 1. $V(t, x)$ is a Liapunov function for (E) if $V(t, x)$ is non-negative, continuous, and locally Lipschitzian on $D$, if $V(t, 0)=0$ for $t \geqq 0$, and $V^{\prime}(t, x) \leqq 0$, where

$$
V^{\prime}(t, x)=\lim \sup _{h \rightarrow 0^{+}} h^{-1}[V(t+h, x+h f(t, x))-V(t, x)] .
$$

Definition 2. $V(t, x)$ is mildly unbounded if for every $T>0$, $V(t, x) \rightarrow+\infty$ as $|x| \rightarrow \infty$ uniformly in $t, 0 \leqq t \leqq T$.

THEOREM. For $f$ as described, the solution $F\left(t, t_{0}, x_{0}\right)$ of $(\mathrm{E})$ can be continued to $\left[t_{0}, \infty\right)$ for every $\left(t_{0}, x_{0}\right) \in D$ if and only if there exists on $D$ a mildly unbounded Liapunov function $V(t, x)$ for $(\mathrm{E})$. Furthermore, this function is positive definite if and only if the zero solution of $(\mathrm{E})$ is stable.

SkETCH OF PROOF. Assume such a function exists. If for some $\left(t_{0}, x_{0}\right)$ $\in D, F\left(t, t_{0}, x_{0}\right)$ cannot be continued to $\left[t_{0}, \infty\right)$, there exists $T>t_{0}$ such that $\left|F\left(t, t_{0}, x_{0}\right)\right| \rightarrow \infty$ as $t \rightarrow T-0$. Since $V$ is mildly unbounded, $V\left(s, F\left(\tau, t_{0}, x_{0}\right)\right) \rightarrow+\infty$ as $\tau \rightarrow T-0$ uniformly on $0 \leqq s \leqq T$, hence, $V\left(\tau, F\left(\tau, t_{0}, x_{0}\right)\right) \rightarrow+\infty$, contradicting $V^{\prime}(t, x) \leqq 0$.

Conversely, suppose all solutions can be continued. For each positive integer $m$, let $\phi_{m}(x)$ be a real-valued $C^{1}$ function on $E^{n}$ such that

$$
\phi_{m}(x)= \begin{cases}1 & \text { if }|x| \leqq m, \\ 0 & \text { if }|x| \geqq m+1,\end{cases}
$$

and consider

\footnotetext{
1 Partially supported by NSF Grant G-24335.
} 
$\left(\mathrm{E}_{m}\right)$

$$
x^{\prime}=\phi_{m}(x) f(t, x),
$$

whose solution we denote by $F_{m}\left(t, t_{0}, x_{0}\right)$, which exists on $[0, \infty)$ for every $\left(t_{0}, x_{0}\right) \in D$. Define

$$
V_{m}(t, x)=\left|F_{m}(0, t, x)\right| \text {. }
$$

It can be shown that for each $m, V_{m}(t, x)$ is a Liapunov function with respect to the original equation $(E)$. Define

$$
V(t, x)=\lim _{m \rightarrow \infty} V_{m}(t, x) .
$$

Then $V$ is a Liapunov function, and it can also be shown that $V$ is mildly unbounded.

If the zero solution of $(\mathrm{E})$ is stable, then, near $x=0$, we may take $V(t, x)=V_{m}(t, x)$ for some $m$, and it follows by familiar arguments (see [4]) that $V_{m}$ is positive definite. Conversely, if $V$ is positive definite, the stability follows by one of Liapunov's original theorems [5], completing the sketch.

This result can be used to generalize some of the so-called asymptotic-stability-in-the-large theorems, where " $V$ is mildly unbounded" replaces the statement " $V$ is infinitely large $[4]$ " or " $V$ is radially unbounded [3]," which both mean that $V(t, x) \rightarrow+\infty$ as $|x| \rightarrow \infty$ uniformly in $t, 0 \leqq t<\infty$.

\section{REFERENCES}

1. H. A. Antosiewicz, A survey of Lyapunov's second method, Annals of Mathematics Studies, No. 41, Princeton Univ. Press, Princeton, N. J., 1958.

2. E. A. Coddington and N. Levinson, Theory of ordinary differential equations, McGraw-Hill, New York, 1955.

3. W. Hahn, Theory and application of Liapunov's direct method, Prentice-Hall, Englewood Cliffs, N. J., 1963.

4. N. N. Krasovski1, Stability of motion, Stanford Univ. Press, Stanford, Calif., 1963.

5. A. M. Liapounoff, Problème général de la stabilitê du mouvement, Annals of Mathematics Studies, No. 17, Princeton Univ. Press, Princeton, N. J., 1949.

6. Aaron Strauss, Liapunov functions and $L^{p}$ solutions of differential equations, Trans. Amer. Math. Soc. (to appear).

UNIVERSITY OF MARYLAND 